\title{
Factors terminating ovarian arrest in long-winged females of a flightless bug, Pyrrhocoris apterus (Heteroptera: Pyrrhocoridae)
}

\author{
RADOMÍR SOCHA \\ Biology Centre ASCR, Institute of Entomology, Branišovská 31, CZ-370 05 České Budějovice, Czech Republic; \\ e-mail: socha@entu.cas.cz
}

Key words. Pyrrhocoridae, macropterous females, ovarian arrest, ovarian growth, pre-oviposition period, Pyrrhocoris apterus

\begin{abstract}
The aim of the present study was to determine the factors that are involved in termination of a non-diapause type of ovarian arrest in the adult macropterous females of a flightless bug, Pyrrhocoris apterus (L.), reared under a long-day (18L : 6D) photoperiod. Application of an active analogue of juvenile hormone, methoprene, to adult macropterous females kept under the above conditions induced precocious termination of ovarian arrest and shortened the length of the pre-oviposition period. The results indicate that a temporary ovarian arrest in spontaneously fasting long-day macropterous females results from a deficiency of juvenile hormone. The length of the pre-oviposition period was shortened and ovarian arrest terminated also by de-alation, high temperature and by a prolonged period of starvation. Mating of long-day macropterous females with reproductively active males had no effect on the length of the pre-oviposition period. There was a relationship between the length of the starvation period and the post-feeding pre-oviposition period. The longer the starvation period, the shorter the period from when food was supplied to first oviposition. The results indicate that depletion of the fat body reserves resulting from prolonged fasting, followed by resumption of food intake are pre-requisites for full activation of the corpus allatum and egg development, and play a role in completion and termination of nondiapause ovarian arrest in long-day macropterous females. This phenomenon was never observed in short-day brachypterous females in reproductive diapause.
\end{abstract}

\section{INTRODUCTION}

The firebug, Pyrrhocoris apterus (L.), is a common Palaearctic species from the family Pyrrhocoridae characterized by a non-functional wing-polymorphism (Socha, 1993; Honěk, 1995). The long-winged (macropterous) and short-winged (brachypterous) specimens of this bug are flightless (Socha \& Zemek, 2000a). Both wing polymorphism and reproductive diapause in this bug are controlled by photoperiod and temperature (Hodek, 1968; Honěk, 1976; Socha, 2001). Under short-day conditions (photophase $<16 \mathrm{~h}$ ), bugs from Czech populations diapause (Hodek, 1968; Saunders, 1983) and virtually all individuals are brachypterous, while under longer days the bugs reproduce and a small percentage (0-14\%) becomes macropterous (Honěk, 1976, 1981).

Macropterous females differ from the brachypterous females in various physiological, biochemical and behavioural parameters, e.g. longer pre-oviposition period (Honěk, 1985; Socha \& Šula, 1996), lower feeding and digestive enzyme activities (Socha et al., 1997, 1998), higher adipokinetic response (Socha \& Kodrík, 1999), higher titre of adipokinetic hormone in the corpora cardiaca and brain (Kodrík et al., 2003), and enhanced walking and dispersal (Socha \& Zemek, 2000b, 2003) associated with lower mating activity (Socha, 2004; Socha \& Zemek, 2004). Macropterous adults of $P$. apterus have well developed flight muscles at the time of dispersal by walking, despite the evolutionary loss of their flight capability (Socha \& Šula, 2006). There is an allocation of resources to flight muscles rather than to ovaries (R. Socha \& J. Šula, unpubl. data) in young adult long-day macropterous females of this bug. Histolysis of flight muscles coincides with increased food intake and egg development (Socha \& Šula, 2006). These data indicate that the trade-off between dispersal and reproduction, involving flight muscle development vs. ovarian growth ("oogenesis-flight" syndrome), which occurs in many flying insects, is also present in wing-polymorphic species that disperse only by walking and is termed the “oogenesis-walking” syndrome (Socha, 2004).

Macropterous females of P. apterus may enter two different types of ovarian arrest; hibernal diapause induced by short-day photoperiods or the temporary inhibition of reproduction in non-diapause females under a long-day photoperiod (Socha \& Šula, 1996). The growth of vitellogenic oocytes in long-day brachypterous females of $P$. apterus is a JH-dependent process (Socha et al., 1991) depending on the full activity of the corpus allatum (CA) - the source of juvenile hormone (JH) (Sláma, 1964). The non-diapause type of ovarian arrest observed in young long-day macropterous females is characterized by the presence of pre-vitellogenic ovaries (Socha \& Šula, 1996; Hodková \& Socha, 2006) and indicates that JH titre in the body of these females is below the threshold necessary for the growth of vitellogenic ovaries. Ovarian arrest is then spontaneously terminated in older long-day macropterous females, but what factors play a role in this termination is unknown.

The aims of the present study were to determine (1) what factors are involved in the termination of the nondiapause ovarian arrest in long-day macropterous females of $P$. apterus, (2) if inhibited reproduction and prolonged 
pre-oviposition period results from a decrease in $\mathrm{JH}$ in the body below the threshold stimulating the growth of vitellogenic ovaries, and (3) whether it is a depletion of energy reserves in the fat body that serves as a stimulus for renewed food intake and termination of the ovarian arrest in long-day macropterous females of this bug. The objective is to elucidate the factors that play a role in the termination of the non-diapause ovarian arrest in long-day macropterous females of $P$. apterus and so improve our understanding of the regulation of reproduction and dispersal in insects with secondarily evolved flightlessness.

\section{MATERIAL AND METHODS}

\section{Experimental animals}

The stock cultures of $P$. apterus, originating from wild populations collected at České Budějovice, Czech Republic $\left(48^{\circ} 59^{\prime} \mathrm{N}, 14^{\circ} 28^{\prime} \mathrm{E}\right)$ were used in the present study (Socha et al., 1997, 1998). All stages from egg to adult were reared under a long-day $(18 \mathrm{~L}: 6 \mathrm{D})$ photoperiod and a constant temperature of $26 \pm 1{ }^{\circ} \mathrm{C}$, which allows the continuous breeding of the bugs. Larvae and adults were kept in glass jars $(0.51)$ in a mass culture (approximately 40 specimens per jar) and supplied with linden seeds (Tilia cordata Miller) and water that were replenished twice a week. Diapausing females were obtained by rearing them from egg to adult under a short-day $(12 \mathrm{~L}: 12 \mathrm{D})$ photoperiod at a constant temperature of $26 \pm 1{ }^{\circ} \mathrm{C}$. Freshly ecdysed adult females of the macropterous morph destined for experimental treatments were transferred to Petri dishes (diameter $6 \mathrm{~cm}$ ) and kept either as single females or with reproductively active brachypterous males under a long-day (18L : 6D) photoperiod and constant temperature of $26 \pm 1{ }^{\circ} \mathrm{C}$. In starvation experiments, the long-day macropterous and short-day brachypterous females were kept under the same conditions in which they developed, but only supplied with water. The length of the pre-oviposition period (pre-OP), i.e. the interval in days between adult emergence and first oviposition, and the length of the post-feeding pre-OP, which is the interval in days between supplying food after starvation and first oviposition, were used as markers of termination of ovarian arrest.

\section{Treatments and surgical procedures}

The effects of the following factors on termination of nondiapause ovarian arrest and the length of the pre-OP in long-day macropterous females of $P$. apterus were analysed: juvenile hormone analogue (methoprene), de-alation, high temperature, mating and starvation.

\section{Hormonal treatments}

Sláma et al. (1974) described and tested many natural and synthetic substances with juvenile hormone $(\mathrm{JH})$ activity on $P$. apterus. To study the role of $\mathrm{JH}$ in termination of ovarian arrest in adult long-day macropterous females, the most active analogue of juvenile hormone ( $\mathrm{JHa})$, methoprene, prepared in the Institute of Organic Chemistry and Biochemistry of the Academy of Sciences of the Czech Republic, Prague, was used in the present study. Methoprene exhibits high JH activity in various heteropterans, including $P$. apterus; in this bug it induces moulting of superlarvae, terminates diapause, and induces the synthesis of vitellogenin and growth of vitellogenic ovaries in allatectomized females (Sláma et al., 1974; Socha et al., 1991). To study the effect of methoprene on the length of the pre-OP, the long-day macropterous females were treated topically with $1 \mu \mathrm{l}$ of an acetone solution containing methoprene $(2 \mu \mathrm{g} / 1 \mu \mathrm{l})$ on the $1 \mathrm{st}$ and 7 th day after adult emergence. Macropterous females of the same age used as controls were treated with $1 \mu \mathrm{l}$ of acetone on the 1 st and 7 th day after adult emergence.

\section{De-alation}

The fore- and hind-wings of long-day adult macropterous females were cut off on the day they emerged. Intact females of the same age were used as controls.

\section{High temperature}

To study the effect of increased temperature on the length of the pre-OP, the freshly ecdysed macropterous females were singly transferred in Petri dishes to an incubator and each kept at a long-day (18L : 6D) photoperiod and temperature of $33^{\circ} \mathrm{C}$.

\section{Mating}

To determine the effect of mating on the length of the pre-OP, long-day macropterous females were kept individually in Petri dishes (diameter $6 \mathrm{~cm}$ ) in pairs with reproductively active brachypterous males, either for the whole observation period (i.e. from day of adult emergence to first oviposition) or only for $8 \mathrm{~h}$. Matings, and fertility of the eggs were recorded. Virgin females kept individually in Petri dishes without males were used as controls.

\section{Starvation}

To determine the effects of food deprivation (artificial starvation) on termination of ovarian arrest of non-diapause type in long-day macropterous females and termination of reproductive diapause in short-day brachypterous females, the following two starvation experiments were performed.

In the first experiment, the freshly emerged macropterous females were first fed on linden seeds and water for three days; afterwards they were kept individually in Petri dishes and supplied with only water. After different periods of starvation (6, 13, 21 and 28 days) the females were again supplied with linden seeds and water and kept under the same photoperiod and temperature. Then, the length of the post-feeding pre-OP, i.e. the interval in days from the time of renewal of food supply to the first oviposition was determined.

In the second experiment, forty 1-month-old diapausing brachypterous females reared under a short-day (12L : 12D) photoperiod and $26 \pm 1{ }^{\circ} \mathrm{C}$ were individually transferred into Petri dishes and divided into two groups. The first (starving) group of 20 females was supplied with water only and starved for the next 3 months under the same photoperiod and temperature conditions; after this period of starvation they were very thin. They were then supplied with linden seeds and water, and kept under the same photoperiodic and temperature regime for the next 2 months. The second (feeding) group of 20 females were supplied with linden seeds and water, and kept individually in Petri dishes from the adult emergence for 5 months under the same photoperiodic and temperature regime; they were used as controls. The length of the post-feeding pre-OP of both the starved and control groups of females, was determined.

\section{Data presentation and statistical analyses}

Statistics were computed and figures prepared with Prism (GraphPad Software, San Diego, CA, USA). A two-tailed $t$ test and one-way ANOVA with Newman-Keuls Multiple Comparison post- test were used to compare the lengths of pre-OP and post-feeding pre-OP of experimental and control females.

\section{RESULTS}

\section{JHa-treatment}

To study the role of $\mathrm{JH}$ in terminating ovarian arrest in long-day macropterous females, they were treated on the 1 st and 7 th day after adult emergence with a high dose (2 


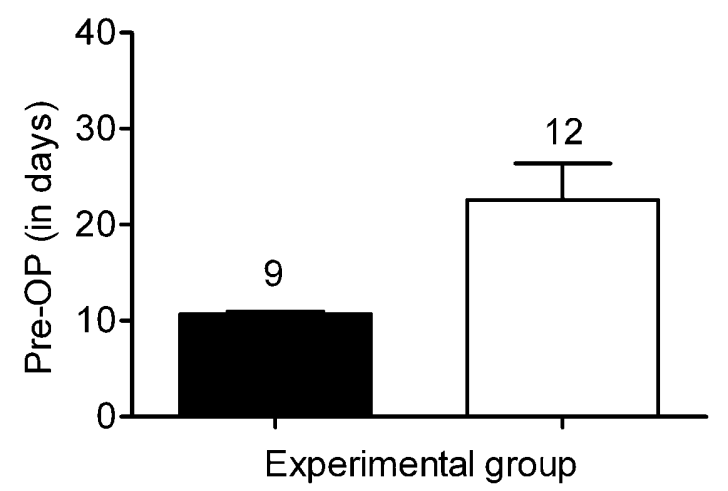

Fig. 1. The effect of methoprene-treatment of long-day macropterous females of $P$. apterus on the length of their pre-OP. Abbreviations and symbols: black bars - methoprene-treated females; white bars - acetone-treated females. The numbers above the bars indicate sample sizes and vertical lines means \pm S.D.

$\mu \mathrm{g}$ ) of the JHa, methoprene. Statistical analysis revealed a significant difference between the lengths of the pre-OP in methoprene-treated macropterous females and acetonetreated controls (Fig. 1). The length of the pre-OP in methoprene-treated macropterous females $(10.67 \pm 0.29$ days) was significantly shorter ( $t$ test: $t_{19}=2.69, P=$ 0.014) than in acetone-treated controls (22.58 \pm 3.79 days). The results indicate that a high dose of $\mathrm{JH}$ accelerated the termination of a non-diapause ovarian arrest in long-day macropterous females of $P$. apterus.

\section{De-alation}

This part of the study revealed a significant effect of de-alation on the termination of ovarian arrest and the length of the pre-OP in long-day macropterous females (Fig. 2). The length of the pre-OP of de-alated macropterous females $(10.50 \pm 0.41$ days $)$ was significantly shorter ( $t$ test: $t_{33}=5.57, P<0.0001$ ) than that of intact controls ( $24.58 \pm 2.29$ days $)$.

\section{High temperature}

When long-day macropterous females were exposed to $33^{\circ} \mathrm{C}$, their ovarian arrest was also precociously termi-

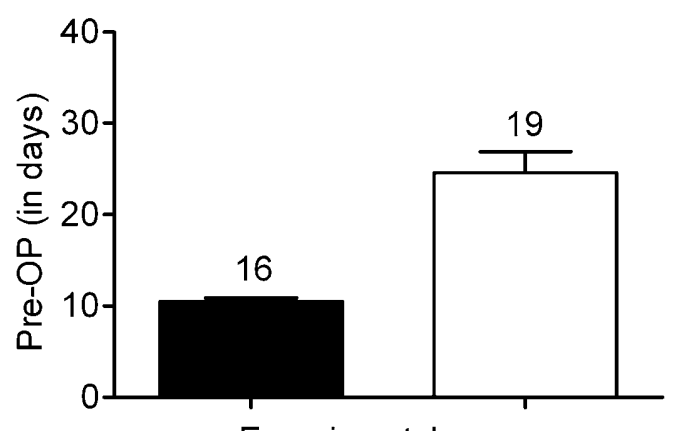

Experimental group

Fig. 2. The effect of de-alation on the length of the pre-OP of long-day macropterous females of $P$. apterus. Abbreviations and symbols: black bars - de-alated females; white bars - intact females. The numbers above the bars indicate sample sizes and vertical lines means \pm S.D.

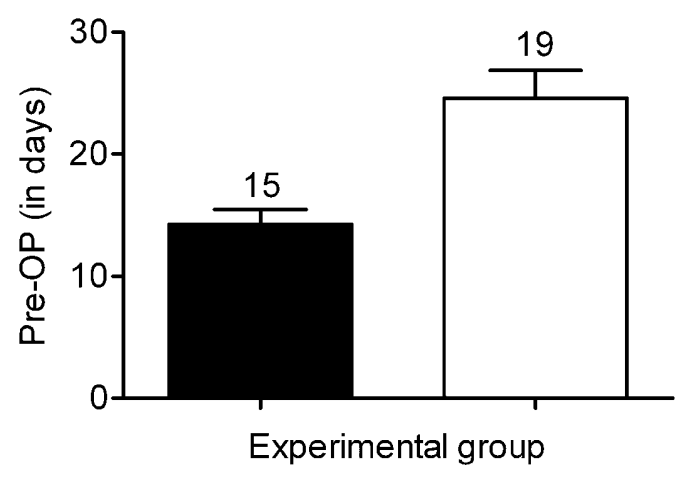

Fig. 3. The effect of temperature on the length of the pre-OP of long-day macropterous females of $P$. apterus. Abbreviations and symbols: black bars - females exposed to $33^{\circ} \mathrm{C}$; white bars - females reared at $26^{\circ} \mathrm{C}$. The numbers above the bars indicate sample sizes and vertical lines means \pm S.D.

nated (Fig. 3). The length of the pre-OP in long-day macropterous females exposed to $33^{\circ} \mathrm{C}(14.27 \pm 1.19$ days $)$ was significantly shorter ( $t$ test: $t_{32}=3.69, P=0.0008$ ) than that in macropterous females kept at $26^{\circ} \mathrm{C}(24.58 \pm$ 2.29 days).

\section{Mating}

This part of the study was devoted to determining whether the ovarian arrest of long-day macropterous females can be precociously terminated by mating with reproductively active males. The lengths of the pre-OPs of three different experimental groups of long-day macropterous females were determined: (1) virgin females, (2) females continuously kept and mated with males until the first oviposition, and (3) females kept and mated with males for only $8 \mathrm{~h}$. Mating of females in the later two experimental groups was observed and the eggs laid by them hatched. No significant differences $(P>0.05)$ in the lengths of the pre-OP were found among these three experimental groups of females (Fig. 4).

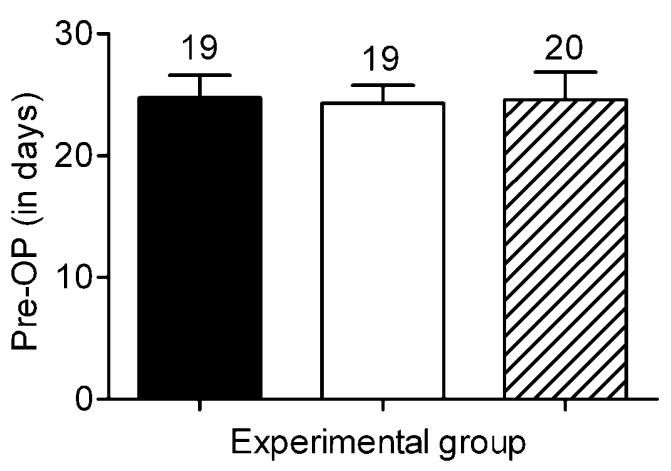

Fig. 4. The effect of mating on the length of the pre-OP of long-day macropterous females of $P$. apterus. Abbreviations and symbols: black bars - females kept and mated with reproductively active males over the whole observation period; white bars - females kept and mated with reproductively active males for only $8 \mathrm{~h}$; hatched bars - virgin females. The numbers above the bars indicate sample sizes and vertical lines the means \pm S.D. 
TABLE 1. The effect of different periods of starvation on the time to 1 st oviposition in long-day macropterous females of $P$. apterus.

\begin{tabular}{cc}
\hline Starvation period (in days) $^{1}$ & $\begin{array}{c}\text { Pre-OP (in days) } \\
\text { Mean } \pm \text { S.D. }(n)\end{array}$ \\
\hline 0 & $24.74 \pm 8.19(19)$ \\
6 & $17.71 \pm 8.94(14)$ \\
13 & $9.89 \pm 5.44(9)$ \\
16 & $7.71 \pm 0.75(24)$ \\
21 & $8.17 \pm 2.04(12)$ \\
26 & $8.00 \pm 1.79(6)$ \\
\hline
\end{tabular}

${ }^{1}$ The length of starvation period is the interval in days from the 4th day of adult life (fed during the first three days of adult life) to the time when the food supply is renewed. The control females were not starved and kept on linden seeds and water for the whole experimental period, i.e. from adult emergence to 1 st oviposition.

${ }^{2}$ For starved females, the post-feeding pre-OP is the interval in days between the time from renewal of food supply to 1st oviposition. In the control (non-starved) females, the pre-OP is the interval in days between adult emergence and 1st oviposition. Abbreviations: S.D. - standard deviation; $n$ - number of females analysed.

\section{Starvation}

The aim of this part of the study was to determine whether starvation of long-day macropterous females affects the length of the post-feeding pre-OP, i.e. the interval in days from the time the food supply is renewed to the first oviposition. The long-day macropterous females were fed on linden seeds and water for the first three days of adulthood and then exposed to different periods of starvation. The results indicate there is a relationship between the length of starvation and that of the post-feeding pre-OP (Table 1): the longer the starvation period, the shorter the post-feeding pre-OP. The length of post feeding pre-OP of non-starved females was significantly longer $(24.74 \pm 8.19$ days $)$ than that of females starved for $6\left(17.71 \pm 8.94\right.$ days, $t$ test: $t_{31}=2.35, P=$ $0.0256), 13\left(9.89 \pm 5.44\right.$ days, $t$ test: $t_{26}=4.92, P<$ $0.0001), 16\left(7.71 \pm 0.75\right.$ days, $t$ test: $t_{41}=10.17, P<$ $0.0001), 21\left(8.17 \pm 2.04\right.$ days, $t$ test: $t_{29}=6.84, P<$ $0.0001)$ or $26\left(8.00 \pm 1.79\right.$ days, $t$ test: $t_{23}=4.90, P<$ $0.0001)$ days. The length of the post-feeding pre-OP of females starved for 6 days was also significantly longer than that of those starved for $13\left(t\right.$ test: $t_{21}=2.35, P=$ 0.0287), 16 ( $t$ test: $\left.t_{36}=5.50, P<0.0001\right), 21\left(t\right.$ test: $t_{24}=$ $3.61, P=0.0014)$ or 26 days $\left(t\right.$ test: $t_{18}=2.60, P=$ $0.0181)$. There were, however, no significant differences (at $P<0.05$ ) between the post-feeding pre-OP of females starved for $13,16,21$ or 26 days. The statistical analysis also showed that the mean lengths of the post-feeding pre-OP of females not starved and starved for 6 days and 13 days had significantly $(P=0.0127-0.0001)$ higher standard deviations than those starved for 16,21 or 26 days. These results indicate that starvation might play an important role in terminating non-diapause ovarian arrest in long-day macropterous females and in synchronizing the time of first oviposition of females starved for longer than 13 days.

On the other hand, there was no significant difference in the lengths of the pre-OP of starved $(12.41 \pm 1.41)$ and fed $(14.67 \pm 11.55)$ groups of short-day brachypterous females ( $t$ test: $\left.t_{3}=0.31, P=0.7775\right)$, which indicates that ovarian arrest in diapausing females kept under a short-day (12L : 12D) photoperiod and temperature of 26 $\pm 1^{\circ} \mathrm{C}$ cannot be precociously terminated by prolonged starvation.

\section{DISCUSSION}

\section{Role of $\mathrm{JH}$ in termination of ovarian arrest}

Application of a high dose of methoprene to long-day macropterous females of $P$. apterus induced precocious growth of vitellogenic ovaries and shortened the average length of the pre-OP. The results indicate that a nondiapause type of ovarian arrest in spontaneously fasting long-day macropterous females results from a low titre of $\mathrm{JH}$, which is below the threshold stimulating growth of vitellogenic ovaries. However, because of the lack of information on the chemical identity of the hemipteran $\mathrm{JH}$ (Davey, 1997; Hodková et al., 2001), the JH titre in the haemolymph of these females could not be determined. However, the results accord with the knowledge that both the synthesis of vitellogenin and growth of vitellogenic ovaries in P. apterus are JH-dependent processes (Socha et al., 1991, 2004) and associated with large size and high activity of the CA (Hodková et al., 2001). The activity of the large $\mathrm{CA}$ of long-day reproductive brachypterous females with vitellogenic ovaries is about four times higher than that of the smaller CA of starved long-day brachypterous and spontaneously fasting long-day macropterous females with pre-vitellogenic ovaries (Hodková et al., 2001, Hodková \& Socha, 2006). The activity of the $\mathrm{CA}$ in young long-day macropterous females is inhibited via nervous connections from the brain (Hodková \& Socha, 2006) as in short-day diapausing and long-day starving brachypterous adult females of $P$. apterus (Hodková, 1976, 1977, 1982), which also show inhibited growth of vitellogenic ovaries. Termination of nondiapause type of ovarian arrest and egg development in older ( $>14$ days old) long-day macropterous females of $P$. apterus after resumption of feeding is most probably the result of the increased volume of their CA (Hodková \& Socha, 2006) and resultant higher JH titre stimulating the growth of vitellogenic ovaries. Stimulation of the CA by feeding also occurs in long-day brachypterous females (Hodková, 1982, 1992). Activation of gonads by JH, methoprene or some other juvenoid occurs in many diapausing insects (Denlinger, 1985; Saunders et al., 1990; Kim \& Krafsur, 1995; Žd'árek et al., 2000), but not in all, e.g. the chrysomelid beetle, Pyrrhalta humeralis in summer diapause (Nakai \& Takeda, 1995a).

\section{The effects of de-alation and mating}

Like methoprene-treated macropterous females of $P$. apterus, de-alated long-day macropterous females of this bug also exhibited precocious growth of vitellogenic ova- 
ries and had shorter pre-OP compared to intact long-day macropterous females. De-alation accelerated termination of ovarian arrest almost to the same extent as the methoprene treatment. Natural de-alation or sheding of the hindwings after adult emergence is a common phenomenon among crickets, but it obviously does not occur in every species and does not always shorten the pre-OP of macropterous females in these insects (Tanaka, 1994). Unlike the de-alated macropterous females of $P$. apterus, de-alation of the cricket Velarifictorus parvus at adult emergence did not influence the length of the pre-OP (Tanaka, 1991). However, accelerated termination of ovarian arrest in the long-day macropterous females of $P$. apterus was observed when they were injured in different ways (Hodková \& Socha, 2006). The injury signal is transmitted to the neuroendocrine complex via the nervous system (Hodková \& Socha, 2006). It induces a higher food intake necessary for repairing and healing of the injured tissues, and subsequently removes the inhibition of the CA, which was temporarily suppressed in spontaneously fasting macropterous adults via the nervous connections from the brain. Wounding is also reported to terminate adult diapause in the Colorado potato beetle, Leptinotarsa decemlineata Say (Rohdendorf \& de Wilde, 1972). Termination of diapause in this species might be a consequence of the changes in metabolism and hormone production caused by injury, since it is known that hormonal systems are involved in regeneration (O'Farell et al., 1960; Pohley, 1961) and wounding increases respiration and protein synthesis associated with healing (Harvey, 1962; Shappirio \& Harvey, 1965).

The present results show that mating long-day macropterous females of $P$. apterus with reproductively active males had no effect on the length of pre-OP and did not lead to precocious termination of ovarian arrest, probably because both virgin macropterous and brachypterous females of this bug develop vitellogenic oocytes and produce eggs (Sláma, 1964). That is, mating does not induce precocious termination of ovarian arrest in long-day macropterous females of this bug. However, in some other insects, mating is obligatory for activation of the CA or stimulates the activity of this endocrine gland (Stay \& Tobe, 1977; Lanzrein et al., 1981). In the large milkweed bug, Oncopeltus fasciatus, male mating behaviour also stimulates ovarian development and enhances egg production in non-diapausing females (Abbott, 1967; Gordon \& Bandal, 1967; Hayes \& Dingle, 1983; Aclé et al., 1990).

\section{Role of temperature in the regulation of ovarian arrest}

In long-day macropterous females of $P$. apterus, an increase in the temperature from $26^{\circ}$ to $33^{\circ} \mathrm{C}$ shortened the length of the pre-OP and induced precocious termination of the non-diapause type of ovarian arrest. High temperature induced precocious termination of the reproductive arrest in these females, even under a short-day photoperiod (R. Socha, unpubl. data). This is not surprising, because it is known that high temperature disrupts hibernal reproductive diapause in short-day bra- chypterous females of this bug (Hodek, 1968) and terminates summer diapause in some other insects, e.g. the chrysomelid beetle, Pyrrhalta humeralis and the zygaenid moth Elcysma westwoodii (Nakai \& Takeda, 1995b). However, higher temperatures in late June to late August also increase the proportion of macropterous specimens in $P$. apterus (Honěk, 1981). It is supposed that the prolonged length of the pre-OP in long-day macropterous females prevents immediate oviposition and establishment of a second generation that would be unable to complete its development before the end of the season (Honěk, 1985). This appears to be the case for most macropterous females that emerge between the end of July and the first decade of August, because a few macropterous females that emerge in the field in the Czech Republic in late June and July begin to develop vitellogenic ovaries and some mate and reproduce (R. Socha, unpubl. data). In macropterous females that emerge between the end of July and the first ten days of August the short-day photoperiod induces transformation of nondiapause ovarian arrest to hibernal diapause. This transformation is accompanied by an accumulation of hexameric proteins in the haemolymph and deposition of energy reserves in the fat body (Socha \& Šla, 1996). On the other hand, most macropterous females that emerged after the first decade of August enter reproductive diapause in response to shortening day length (Honěk, 1981).

High temperature most probably enhances walking activity in flightless macropterous females and accelerates the depletion of the energy reserves in their fat bodies. Since the rate of depletion of the fat body reserves in spontaneously fasting macropterous females must occur quicker at $33^{\circ} \mathrm{C}$ than at $26^{\circ} \mathrm{C}$, the length of the pre-OP is also substantially shorter at higher temperatures. It is probable that termination of non-diapause reproduction arrest by high temperature in long-day macropterous females of $P$. apterus is induced not by changes in the bugs' sensitivity to photoperiod, as occurs in some insects (Danks, 1987), but by depletion of fat body reserves.

\section{Role of starvation and depletion of energy reserves in termination of ovarian arrest}

The present study revealed a negative relation between the length of starvation and that of the post-feeding pre-OP. The longer the period of starvation, the shorter was the period from the time of the renewal of food supply to first oviposition. These results also revealed a marked synchronization in the time of first oviposition in long-day macropterous females starved for longer than 13 days. It appears that depletion of the fat body reserves in spontaneously fasting macropterous females below the level critical for survival might be a "SOS" stimulus for resumption of food intake to the level characteristic for normally feeding reproductive brachypterous females. Resumption of food consumption by long-day macropterous females ( $>14$ days old) results in activation of the $\mathrm{CA}$, which terminates reproduction arrest and induces egg development. These results accord with the finding that food intake also stimulates the growth and gonadotropic 
activity of the CA in long-day brachypterous females of P. apterus (Hodková, 1982). In the cockroach, Blattella germanica, food ingestion also precedes an increase in the volume of the $\mathrm{CA}$, which in turn precedes $\mathrm{JH}$ production, whereas this does not occur in starved females (Osorio et al., 1998). Biosynthesis of JH by the CA is strongly influenced by brain neuropeptides (Gäde \& Hoffmann, 2005), but the role of brain regulators in the morph-specific differences is unknown. McNeil \& Tobe (2001) supposed that changes in allatostatin and allatotropin are associated with migration and/or reproduction in Pseudaletia unipuncta and some other insects. It cannot be excluded that a similar hormonal mechanism might also play a role in the regulation of dispersal and reproduction in long-day macropterous females of $P$. apterus. It appears that the termination of non-diapause ovarian arrest in macropterous females in wild populations $P$. apterus that begin feeding again occurs after prereproductive dispersal activity by walking, which depletes their fat body reserves. This mechanism might not only play an important role in the "oogenesis-walking" syndrome in macropterous females of P. apterus, but also in the "oogenesis-flight" syndrome of some flying monomorphic or wing-polymorphic insects with prereproductive migratory activity (Johnson, 1969). In the migratory grasshopper, Melanoplus sanguinipes, performance of long flights accelerates the onset of first reproduction (Min et al., 2004). These authors found that although the adipokinetic hormone is released during flight and controls lipid mobilization, it is not the factor responsible for the increase in the post-flight $\mathrm{JH}$ titre in this insect. It cannot be excluded, however, that it is the depletion of fat body reserves or their decrease below some critical level that serves as a stimulus for the postflight increase in $\mathrm{JH}$ titre in this species.

It is known that the feeding activity of short-day diapausing brachypterous females ( $>10$ days old) is similar to that of long-day macropterous females in non-diapause ovarian arrest (Šula et al., 1998; Socha \& Zemek, 2006, R. Socha \& R. Zemek, unpubl. data). The question is whether the ovarian arrest in diapausing short-day brachypterous females of $P$. apterus can also be terminated by progressive depletion of fat body reserves (i.e. without changes in the photoperiodic and/or temperature conditions), as in long-day macropterous females. The present comparative study revealed that while the resumption of feeding by starved long-day macropterous females induced precocious growth of vitellogenic ovaries and egg development, this was not observed in diapausing brachypterous females treated similarly. This indicates different mechanisms of CA inhibition in long-day macropterous and short-day diapausing brachypterous females of $P$. apterus. Reciprocal transplantations of the neuroendocrine brain-corpora cardiaca-corpus allatum (BR-CC-CA) complex between brachypterous and macropterous females show that suppression of the $\mathrm{CA}$ in long-day macropterous females of $P$. apterus results from a combination of the "diapause-like" refractoriness of the BR-CC-CA complex to internal milieu and starvation-like inhibition of the CA growth (Hodková \& Socha, 2006). The question that remains to be answered is: What terminates non-diapause ovarian arrest in long-day macropterous females of this bug? Is it a prolonged starvation that progressively removes the "diapause-like" refractoriness of the BR-CC-CA complex of long-day macropterous females and increases its sensitivity to the internal milieu? If this is the case, then the progressive depletion of the fat body by starvation should result in a progressive completion of non-diapause ovarian arrest in long-day macropterous females, even before full feeding is restored. In which case, the renewed food intake only makes the completion of non-diapause arrest apparent. Or, alternatively, depletion of fat body reserves triggers resumption of food intake, which activates the CA and terminates the ovarian arrest in long-day macropterous females of $P$. apterus. This alternative is supported by the finding that feeding serves as a direct trigger removing the inhibition of CA in brachypterous females of this bug and the stimulation due to feeding can be transmitted to a transplanted BR-CC-CA complex via the haemolymph (Hodková, 1982, 1992). Testing the above alternatives by transplantation experiments will be the subject of the next investigation.

ACKNOWLEDGEMENTS. This study was supported by the Institute project No. Z50070508 obtained from the Academy of Sciences of the Czech Republic. The author thanks to D. Rienesslová for technical assistance.

\section{REFERENCES}

Аввотт C.E. 1967: Male influence on ovarian development in the large milkweed bug, Oncopeltus fasciatus (Hemiptera: Lygaeidae). Ann. Entomol. Soc. Am. 60: 344-347.

Aclé D., Brookes V.J., Pratt G.E. \& Feyereisen R. 1990: Activity of the corpora allata of adult female Leucophaea maderae: Effects of mating and feeding. Arch. Insect Biochem. Physiol. 14: 121-129.

DANKs H.V. 1987: Insect Dormancy: An Ecological Perspective. Biological Survey of Canada Monograph No. 1, Natl. Mus. Nat. Sci., Ottawa, 439 pp.

DAVEY K.G. 1997: Hormonal controls on reproduction in female Heteroptera. Arch. Insect Biochem. Physiol. 35: 443-453.

Denlinger D.L. 1985: Hormonal control of diapause. In Kerkut G.A. \& Gilbert L.I. (eds): Comprehensive Insect Physiology, Biochemistry and Pharmacology. Vol. 8. Pergamon Press, Oxford, pp. 353-412.

GÄDE G. \& HoffmanN H. 2005: Neuropeptides regulating development and reproduction in insects. Physiol. Entomol. 30: 103-121.

GoRdON H.T. \& BANDAL S.K. 1967: Effect of mating on egg production by the large milkweed bug, Oncopeltus fasciatus (Hemiptera: Lygaeidae). Ann. Entomol. Soc. Am. 60: 1099-1102.

Harvey W.R. 1962: Metabolic aspects of diapause. Annu. Rev. Entomol. 7: 57-80.

Hayes J.L. \& Dingle H. 1983: Male influence on the duration of reproductive diapause in the large milkweed bug, Oncopeltus fasciatus. Physiol. Entomol. 8: 251-256.

Hodek I. 1968: Diapause in females of Pyrrhocoris apterus L. (Heteroptera). Acta Entomol. Bohemoslov. 65: 422-435.

HodKové M. 1976: Nervous inhibition of corpora allata by photoperiod in Pyrrhocoris apterus. Nature 263: 521-523. 
Hodková M. 1977: Size and gonadotropic activity of corpus allatum after different surgical treatments in Pyrrhocoris apterus females (Heteroptera). Věst. Čs. Spol. Zool. 41: 8-14.

HoDKovÁ M. 1982: Interaction of feeding and photoperiod in regulation of the corpus allatum activity in females of Pyrrhocoris apterus L. (Hemiptera). Zool. Jb. Physiol. 86: 477-488.

HodKovÁ M. 1992: Storage of the photoperiodic "information" within the implanted neuroendocrine complexes of the linden bug, Pyrrhocoris apterus (L.) (Heteroptera). J. Insect Physiol. 38: $357-363$.

Hodková M. \& Socha R. 2006: Endocrine regulation of the reproductive arrest in the long winged females of a flightless bug, Pyrrhocoris apterus (Heteroptera: Pyrrhocoridae). Eur. J. Entomol. 103: 523-529.

Hodková M., OKuda T. \& Wagner R.M. 2001: Regulation of corpora allata in females of Pyrrhocoris apterus (Heteroptera) (a mini-review). In Vitro Cell. Dev. Biol. Anim. 37: 560-563.

HoNĚK A. 1976: Factors influencing the wing polymorphism in Pyrrhocoris apterus (Heteroptera, Pyrrhocoridae). Zool. Jb. Syst. 103: 1-22.

HoNĚK A. 1981: Temperate and wing polymorphism in natural populations of Pyrrhocoris apterus L. (Heteroptera, Pyrrhocoridae). Zool. Jb. Syst. 108: 487-501.

HoNĚK A. 1985: Ecophysiological differences between brachypterous and macropterous morphs in Pyrrhocoris apterus (Heteroptera, Pyrrhocoridae). Acta Entomol. Bohemoslov. 82: 347-354.

HoNĚK A. 1995: Factors and consequences of a non-functional alary polymorphism in Pyrrhocoris apterus (Heteroptera: Pyrrhocoridae). Res. Popul. Ecol. 37: 111-118.

Johnson B. 1969: Migration and Dispersal of Insects by Flight. Methuen, London, 763 pp.

KIM Y. \& KRAFSUR E.S. 1995: In vivo and in vitro effects of 20hydroxyecdysone and methoprene on diapause maintenance and reproductive development in Musca autumnalis. Physiol. Entomol. 20: 52-58.

Kodrík D., Socha R. \& Syrová Z. 2003: Developmental and diel changes of adipokinetic hormone in CNS and haemolymph of the flightless wing-polymorphic bug, Pyrrhocoris apterus (L.). J. Insect Physiol. 49: 53-61.

LANZerein B., Wilhelm R. \& Buschor J. 1981: On the regulation of the corpora allata activity in adult females of the ovoviviparous cockroach Nauphoeta cinerea. In Pratt G.E. \& Brooks G.T. (eds): Juvenile Hormone Biochemistry, Action, Agonism and Antagonism. Elsevier / North-Holland Biomedical Press, Amsterdam, pp. 147-160.

McNeIL J.N. \& Tobe S.S. 2001: Flights of fancy: possible role of allatostatin and allatotropin in migration and reproductive success of Pseudaletia unipunctata. Peptides 22: 271-277.

Min J.K., Jones N., Borst D.W. \& Rankin M.A. 2004: Increased juvenile hormone levels after long-duration flight in the grasshopper, Melanoplus sanguinipes. J. Insect Physiol. 50: $531-537$.

NAKAi T. \& TAKedA M. 1995a: Failure of juvenoid and solvent treatments to terminate summer diapause in Pyrrhalta humeralis (Coleoptera: Chrysomelidae). Appl. Entomol. Zool. 30: 295-301.

NAKAI T. \& TAKEDA M. 1995b: Effect of temperature on the estivation of Elcysma westwoodii (Lepidoptera, Zygaenidae). Appl. Entomol. Zool. 30: 594-596.

O'Farrell A.F., Stock A., Rae C.A. \& Morgan J.A. 1960: Regeneration and development in the cockroach Blattella germanica. Acta Entomol. Bohemoslov. 57: 317-324.

Osorio S., Piulachs M.D. \& Bellés X. 1998: Feeding and activation of corpora allata in the cockroach Blattella germanica (L.) (Dictyoptera, Blattellidae). J. Insect Physiol. 44: 31-38.
Pohley H.J. 1961: Interactions between the endocrine system and the developing tissue in Ephestia kuhniella. Roux's Arch. Dev. Biol. 153: 443-458.

RoHDENDORF E. \& DE WILDE J. 1972: Wounding effects as a factor breaking diapause in the adult Colorado potato beetle (Leptinotarsa decemlineata Say). In Novák V.J.A. \& Sláma K. (eds): Insect Endocrines III. Academia, Praha, pp. 99-101.

SAUNDERS D.S. 1983: A diapause induction-termination asymmetry in the photoperiodic responses of the linden bug, Pyrrhocoris apterus and an effect of near-critical photoperiods on development. J. Insect Physiol. 29: 399-405.

Saunders D.S. \& Richard D.S., Applebaum S.W., Ma M. \& Gilbert L.I. 1990: Photoperiodic diapause in Drosophila melanogaster involves a block to juvenile hormone regulation of ovarian maturation. Gen. Comp. Endocrinol. 79: 174-184.

Shappirio D.G. \& Harvey W.R. 1965: The injury metabolism of the cecropia silkworm II. Injury-induced alterations in oxidative enzyme systems and respiratory metabolism of the pupal wing epidermis. J. Insect Physiol. 11: 305-327.

SLÁMA K. 1964: Hormonal control of respiratory metabolism during growth, reproduction, and diapause in female adults of Pyrrhocoris apterus L. (Hemiptera). J. Insect Physiol. 10: 283-303

Sláma K., Romañuk M. \& Šorm F. 1974: Insect Hormones and Bioanalogues. Springer Verlag, Wien, 387 pp.

Socha R. 1993: Pyrrhocoris apterus (Heteroptera) - an experimental model species: a review. Eur. J. Entomol. 90: 241-286.

Socha R. 2001: Latitudinal gradient in response of wing polymorphism to photoperiod in a flightless bug, Pyrrhocoris apterus (Heteroptera: Pyrrhocoridae). Eur. J. Entomol. 98: 167-169.

SochA R. 2004: Decreased mating propensity of macropterous morph in a flightless wing-polymorphic insect, Pyrrhocoris apterus (L.) (Heteroptera). Eur. J. Entomol. 101: 539-545.

Socha R. \& Šula J. 1996: Differences in haemolymph proteins in relation to diapause and wing dimorphism in Pyrrhocoris apterus (L.) (Heteroptera). J. Comp. Physiol. (B) 166: 382-387.

SochA R. \& KodRíK D. 1999: Differences in adipokinetic responses of Pyrrhocoris apterus (Heteroptera) in relation to wing dimorphism and diapause. Physiol. Entomol. 24: 278-284.

Socha R. \& Šula J. 2006: Flight muscles polymorphism in a flightless bug, Pyrrhocoris apterus (L.): developmental pattern, biochemical profile and endocrine control. J. Insect Physiol. 52: 231-239.

SOCHA R. \& ZEMEK R. 2000a: Wing movement behavior in longand short-winged morphs of flightless bug Pyrrhocoris apterus L. (Heteroptera: Pyrrhocoridae). J. Insect Behav. 13: 741-750.

Socha R. \& ZemeK R. 2000b: Locomotor activity in adult Pyrrhocoris apterus (Heteroptera) in relation to sex, physiological status and wing dimorphism. Physiol. Entomol. 25: 383-389.

Socha R. \& Zemek R. 2003: Wing morph-related differences in the walking pattern and dispersal in a flightless bug, Pyrrhocoris apterus (L.) (Heteroptera). Oikos 100: 35-43.

SOCHA R. \& ZEMEK R. 2004: Mating behaviour and wing morphrelated differences in the sexual activity of a flightless bug, Pyrrhocoris apterus (L.) (Heteroptera). Ethol. Ecol. Evol. 16: 217-229.

Socha R. \& Zемeк R. 2006: Temporal pattern of feeding activity in the firebug Pyrrhocoris apterus and its relation to sex, wing dimorphism and physiological state of adults. Physiol. Entomol. 31 (in press). 
Socha R., Šula J., Kodrík D. \& Gelbič I. 1991: Hormonal control of vitellogenin synthesis in Pyrrhocoris apterus (L.) (Heteroptera). J. Insect Physiol. 37: 805-816.

Socha R., Šula J. \& ZemeK R. 1997: Feeding, drinking and digestive enzyme activities in long- and short-day females of Pyrrhocoris apterus (Heteroptera). Physiol. Entomol. 22: 161-169.

Socha R., Šula J. \& Zemek R. 1998: Feeding behaviour, digestive physiology and lipid content in macropterous females of Pyrrhocoris apterus (L.) (Heteroptera: Pyrrhocoridae). Physiol. Entomol. 23: 91-96.

Socha R., ŠUla J. \& KodríK D. 2004: Wing morph-related differences in developmental pattern of accessory gland proteins in adult males of Pyrrhocoris apterus (L.) and their endocrine control. J. Insect Physiol. 50: 893-901.

Stay B. \& Tobe S.S. 1977: Control of juvenile hormone biosynthesis during the reproductive cycle of a viviparous cockroach. I. Activation and inhibition of corpora allata. Gen. Comp. Endocrinol. 33: 531-540.

Šula J., Socha R. \& Zemek R. 1998: Wing- morph-related physiological differences in adults of temperate population of Pyrrhocoris apterus (L.) (Heteroptera: Pyrrhocoridae). Сomp. Biochem. Physiol. (A) 121: 365-373.

TANAKA S. 1991: De-alation and its influence on egg production and flight muscle histolysis in a cricket (Velarifictorus parvus) that undergoes inter-reproductive migration. $J$. Insect Physiol. 37: 517-523.

TANAKA S. 1994: Evolution and physiological consequences of de-alation in crickets. Res. Popul. Ecol. 36: 137-143.

ŽĎÁrek J., ČTVRTeČKa R., Hovorka O. \& KošŤÁl V. 2000: Activation of gonads and disruption of imaginal diapause in the apple blossom weevil, Anthonomus pomorum (Coleoptera: Curculionidae), with juvenoids in laboratory and field trials. Eur. J. Entomol. 97: 25-31.

Received April 21, 2006; revised and accepted July 24, 2006 